\title{
CAPÍTULO 49: ANÁLISE DO PERFIL DOS CONSUMIDORES DE LEITE CONDENSADO, DOCE DE LEITE E SOBREMESAS LÁCTEAS NO ESTADO DE PERNAMBUCO
}

\section{CHAPTER 49: PROFILE ANALYSIS OF CONSUMERS OF CONDENSED MILK, SWEET MILK AND MILK DESSERTS IN THE STATE OF PERNAMBUCO}

Fabiana Maria da Silva ${ }^{1}$; Ádilla Pereira d'Ávila Souza²; Jéssyca Karolina de Lima Santos ${ }^{3}$; Gerla Castello Branco Chinelate ${ }^{4}$

\begin{abstract}
Resumo
No primeiro semestre de 2020, houve um aumento no preparo de comidas caseiras, devido ao isolamento social causado pela Covid-19. Resultados de estudos mostraram que, neste período, ocorreu um aumento no consumo de doce de leite, sorvete e leite condensado, alimentos caracterizados como indulgentes. O objetivo deste trabalho foi traçar o perfil dos consumidores desses produtos lácteos e indicar os fatores que influenciam a compra desses produtos. Para tanto, 157 consumidores voluntários responderam um questionário contendo perguntas relacionadas ao consumo dos lácteos abordados. Os resultados evidenciaram que a maioria dos respondentes são jovens entre 16 e 25 anos, residentes do agreste pernambucano que consomem os produtos a cada 15 dias. Quando questionados sobre a influência da pandemia no consumo, aproximadamente $63 \%$ notaram um aumento no valor de algum desses produtos e acreditam que esteja relacionado com a pandemia. $\mathrm{O}$ resultado desse estudo destaca o aumento do consumo dos supracitados derivados lácteos no período da pandemia, demonstrando o apreço do consumidor por alimentos indulgentes em períodos de estresse, associado a um maior tempo em casa e reafirma a influência da confiabilidade na marca no momento de indicar um produto.
\end{abstract}

Palavras-Chave: Segurança alimentar, consumo, derivados lácteos, alimentos indulgentes, Covid-19, comfort food.

\begin{abstract}
\footnotetext{
${ }^{1}$ Engenharia de Alimentos, UFAPE, fabianamariax@ gmail.com

${ }^{2}$ Engenharia de Alimentos, UFAPE, adillapereira@hotmail.com

${ }^{3}$ Engenharia de Alimentos, UFAPE, jessycakarolinals@gmail.com

${ }^{4}$ Doutora em Biotecnologia, Docente da UFAPE, gerla.chinelate@ufape.edu.br
}

In the first half of 2020, there was an increase in the preparation of homemade foods, due to the social isolation caused by Covid-19. Results of studies showed that in this period there was an increase in the consumption of milk jam, ice cream and condensed milk, foods characterized as indulgent. The objective of this work was to outline the profile of consumers of these dairy products and indicate the factors that influence the purchase of these products. To this end, 157 voluntary consumers answered a questionnaire containing questions related to the consumption of the dairy products addressed. The results showed that most of the respondents are young people between 16 and 25 years of age, residents of the agreste Pernambucano who consume the products every 15 days. When asked about the influence of the pandemic on consumption, approximately $63 \%$ noticed an increase in the value of some of these products and believe it is related to the 
pandemic. The result of this study highlights the increased consumption of the aforementioned dairy products during the pandemic period, demonstrating the consumer's appreciation of indulgent food in periods of stress, associated with a longer time at home and reaffirms the influence of reliability in the brand when indicating a product.

Keywords: Food safety, consumption, dairy products, indulgent foods, Covid-19, comfort food.

\section{Introdução}

Pernambuco tem uma extensão territorial de $98.067,881 \mathrm{~km}^{2}$ e uma população estimada de 9.557.071 pessoas (IBGE, 2019). Dentre os estados do Nordeste, Pernambuco é o segundo maior produtor de leite, com 21,9\% do total de leite produzido na Região Nordeste, ficando atrás somente da Bahia que representa $31 \%$ da produção regional (SEBRAE, 2013). Apesar do Estado ocupar a segunda posição em termos quantitativos de produção de leite, é o sexto em consumo alimentar médio per capita (kg/ano) de leite e derivados, atrás do Ceará, Rio Grande do Norte, Bahia, Paraíba e Sergipe (SEBRAE, 2013).

A agilidade do dia a dia compromete o preparo de refeições, em virtude do menor tempo, adaptando nossa refeição para o momento conveniente, muitas vezes fora de casa. No período de isolamento, além das orientações de higiene e segurança recomendadas pela Organização Mundial de Saúde (OMS), veio o estímulo de consumir alimentos mais saudáveis para melhorar o quadro de saúde e diminuir as chances de uma imunidade frágil contra a Covid-19 para tal, surgiu a necessidade de voltar a cozinhar, a busca por alimentos saudáveis tornou-se inevitável, bem como, a retomada de hábitos já esquecidos. Para SCHUBERT (2020) essas mudanças que estamos adotando em relação aos nossos hábitos alimentares, bem como as dinâmicas de trabalho e deslocamento são resultados dessa pandemia causada pelo novo coronavírus.

É possível notar que houve um aumento no consumo de alimentos lácteos. De acordo com a UFJF (2020) um estudo coordenado Embrapa Gado de leite em parceria com Universidade Federal de Juiz de Fora (UFJF), os pesquisadores objetivaram verificar a opinião dos internautas quando ao consumo de produtos lácteos no período da quarentena, como resultado os alimentos que foram mais comentados no tweet que estavam relacionados ao coronavírus foram: sorvete, leite condensado, lactose, manteiga e doce de leite. Alguns desses são alimentos conhecidos como indulgentes, aqueles que proporcionam prazer e felicidade a quem os consome. A Indulgência está ligada ao prazer e os produtos indulgentes têm uma forte carga de regionalismo, já que passam pelo desenvolvimento do hábito de consumo (SEBRAE, 2017). 
Através desse estudo, objetivou-se traçar o perfil dos consumidores de leite condensado, doce de leite e sobremesas lácteas no estado de Pernambuco durante o cenário da pandemia, analisando quais os principais fatores que influenciam no consumo desses alimentos.

\section{Material e Métodos}

Foi realizado levantamento de artigos científicos, teses, dissertações, textos e livros do período de 2015 - 2020 nas bases de dados Scielo, Scopus e do portal CAPES, bem como a busca de textos atualizados em sites.

Os descritores utilizados para doce de leite foram: consumo de doce de leite, análise socioeconômica dos consumidores de doce de leite, padrão de consumo de doce de leite e perfil dos consumidores de doce de leite. Para o leite condensado e sobremesa láctea utilizamos como base os mesmos descritores, alterando apenas o produto.

A pesquisa para levantamento de dados foi realizada de modo individual para obtenção de maiores informações relacionadas aos produtos, devido a carência de trabalhos que discutem simultaneamente os três alimentos em discussão. Enquanto que, no questionário foram abordados em conjunto para oferecer praticidade e otimização de tempo atingindo o maior número de respondentes.

O perfil dos consumidores de leite condensado, doce de leite e sobremesas lácteas no estado de Pernambuco foi obtido através de um levantamento de dados realizados pela equipe do Grupo de Pesquisa e Desenvolvimento de Produtos Lácteos e Gestão Industrial - GPLAC da Universidade Federal do Agreste de Pernambuco - UFAPE no período de 30 de junho a 30 de julho de 2020. O questionário foi elaborado através da plataforma do Google Forms, de acesso público, online e gratuito.

O questionário de 38 perguntas buscou investigar dados pessoais, socioeconômicos, hábitos e o consumo dos produtos lácteos, leite condensado, sobremesa láctea e doce de leite, as perguntas elaboradas auxiliaram na observação direta das seguintes variáveis: Análise da frequência de consumo, percepção dos hábitos no consumo de produtos lácteos, quantidades e locais de aquisição, tipos mais conhecidos, formas de consumo, influências no momento da compra, aceitação dos produtos e as características sociais e demográficas dos consumidores. A avaliação estatística foi feita com o auxílio da ferramenta Microsoft Excel. 


\section{Resultados e Discussão}

O questionário do Google Forms atingiu 174 respostas, porém 17 declararam não morar em Pernambuco, resultando em 157 respostas válidas para a pesquisa. Os 157 indivíduos estavam dispostos em 4 regiões de Pernambuco a maioria 82,2\% (129) no agreste, 8,9 \% (14) na zona da mata, 5,7\% (9) região metropolitana e 3,2 \% (5) sertão, e a sua maioria $86,0 \%$ (135) residia em zona urbana e os demais (22) em zona rural. Onde $62,4 \%$ (98) eram do sexo feminino e 37,6\% (59) do sexo masculino, em relação à faixa etária, a maioria 75,8\% tinha entre 16 e 25 anos, $12,1 \%$ tinham entre 26 e 35 anos, 8,9\% tinham entre 36 e 45 anos, 1,9\% tinham entre 46 e 55 anos, 0,6 \% tinha entre 56 e 65 anos, assim como 0,6 \% tinha mais de 65 anos. Por se tratar de um questionário online, os dados do público entrevistado dependem diretamente do perfil de quem possui rede social e do público atingido por quem divulgou o questionário.

A maioria dos indivíduos possuía como nível de alfabetização o superior incompleto 49,7\% (78), médio completo $19,1 \%$ (29), pós-graduação completa 9,6 \% (15), médio incompleto 18,5\% (13), 6,4 \% (10) superior completo, pós-graduação incompleta $5,1 \%$ (8), fundamental incompleto $1,9 \%$ (3) e $0,6 \%$ (1) fundamental completo. Em relação à renda dos indivíduos, a 35,7 \% (56) apresentam renda de até 1 salário mínimo, 46,5\% (73) tinha a renda entre 1 e 3 salários mínimos, 14,0 \% (22) tinha a renda de 3 a 6 salários mínimos, 1,9 \% (3) recebiam entre 6 e 9 salários mínimos; e outros $1,9 \%$ (3) indivíduos tinha renda superior a 9 salários mínimos. Observou-se ainda que 77,7 \% (122) destes participam de algum programa de ajuda do governo, com exceção do auxílio emergencial. 
Figura 1. Consumo de leite condensado, doce de leite e sobremesa láctea pelos respondentes.

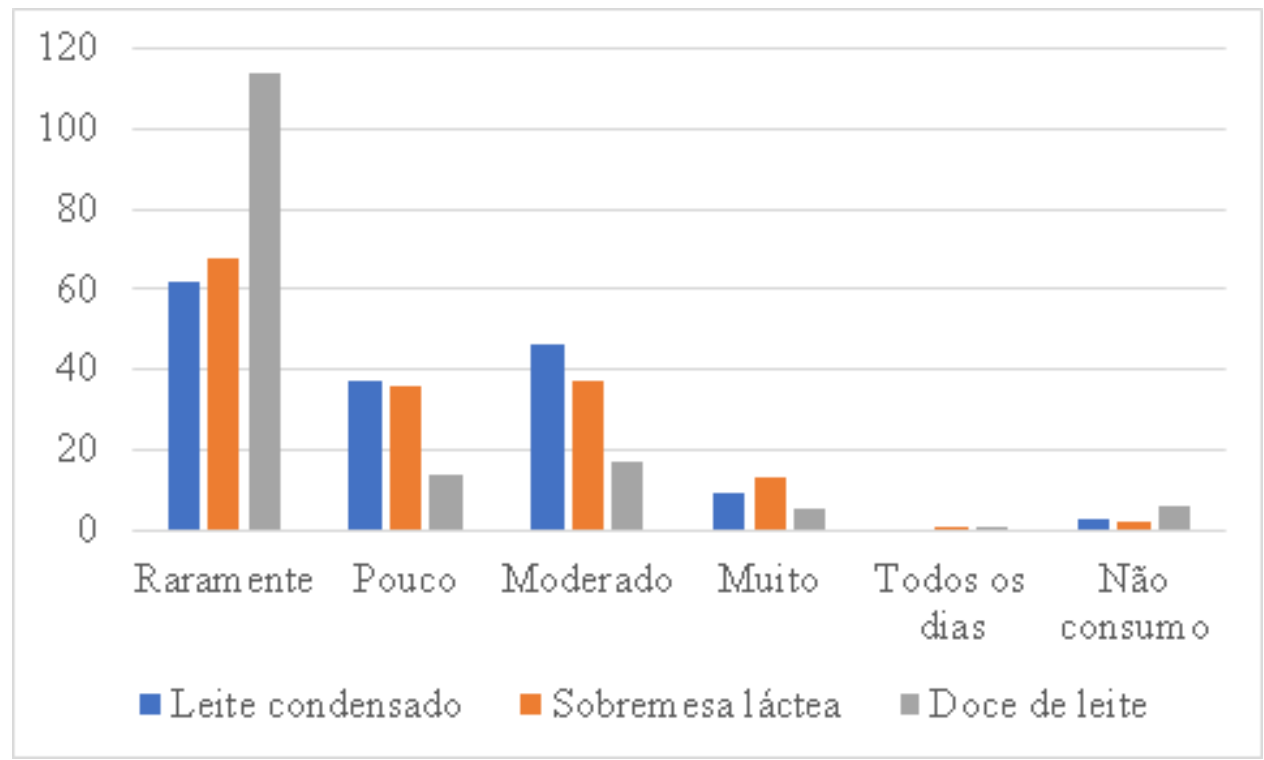

Fonte: Própria (2020)

O consumo (Figura 1) de um alimento é considerado frequente quando a sua ingestão é maior ou igual a 4 vezes na semana, e apenas $8,3 \%$ dos indivíduos afirmaram que consomem sobremesa láctea nessas proporções, 5,7 \% o leite condensado e apenas $3,2 \%$ o doce de leite. Estes produtos não ocupam posição de destaque quanto ao consumo diário, a maioria dos indivíduos relataram que o consumo do doce de leite $(72,6 \%)$, sobremesa láctea $(43,3)$ e leite condensado $(39,5 \%)$ é raro sendo uma vez a cada 15 dias. Ao consumir esses produtos as principais emoções (Figura 2) que os indivíduos sentiram foram felicidade $(64,1 \%)$, prazer $(64,3 \%)$, bem $(50,7 \%)$, satisfação $(49,7 \%)$ e alegria $(44,1 \%)$. Isso se dá ao fato de que os produtos discutidos fazem parte dos alimentos indulgentes e do "comfort food", aqueles que oferecem sensação de prazer a quem consome. Minasse (2016) já falava que as comidas que recebem o nome de indulgentes foram associadas a situações em que têm seu valor nutricional deixado de lado, nesses alimentos e bebidas a prioridade está no prazer obtido ao consumi-los. 
Figura 2. Emoções causadas pelo consumo de doce de leite, leite condensado e sobremesas lácteas.

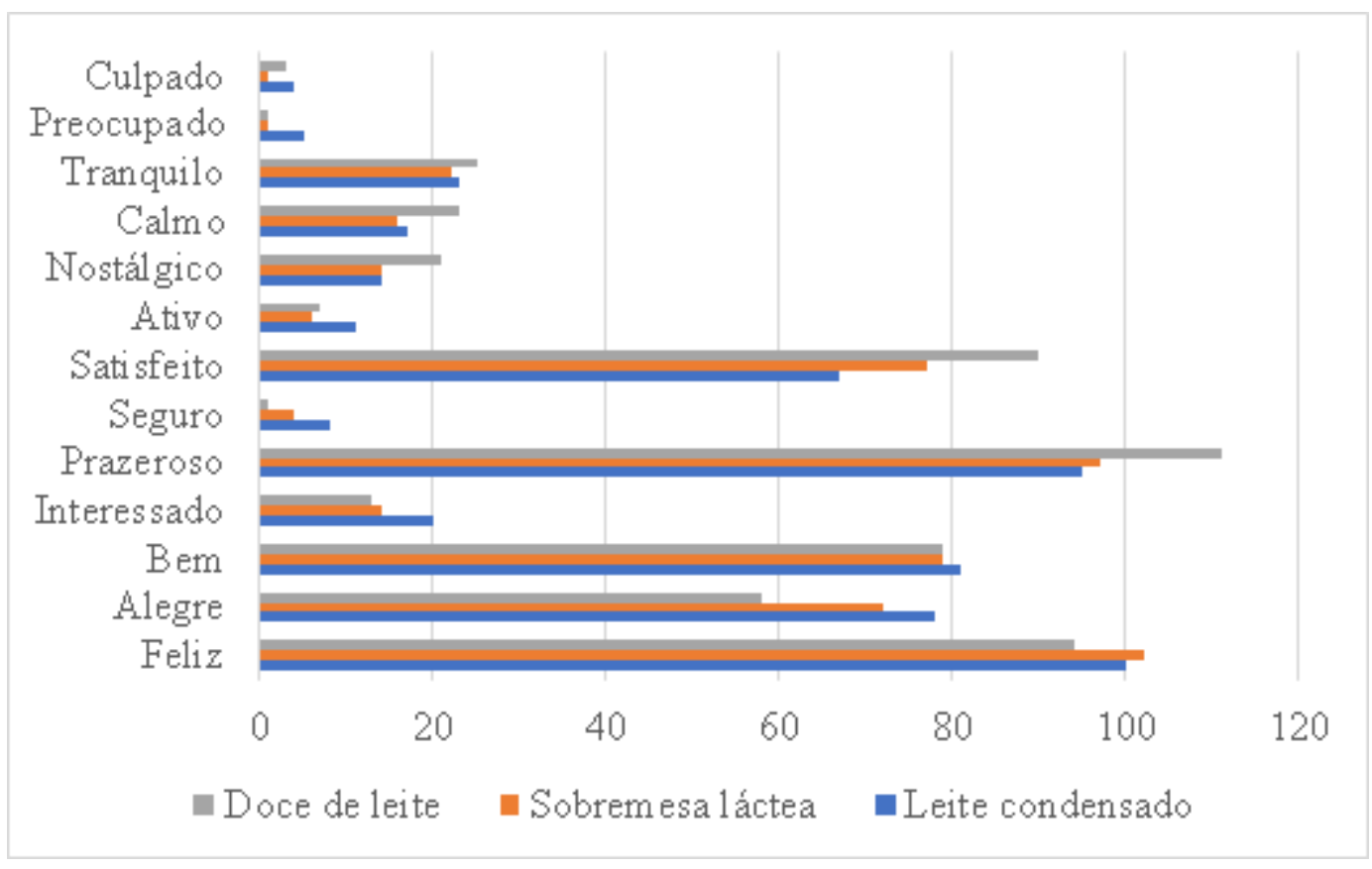

Fonte: Própria (2020)

No momento da compra 99,4\% adquire (Figura 3) o leite condensado em supermercados e o restante $(2,5 \%)$ em feiras, isso em razão de que esses alimentos são encontrados com maior frequência em supermercados. Para embalagem a preferência $(88,5 \%)$ se dar a ele em caixa do que em lata. Assim como o doce de leite que 89,2\% adquire em supermercados e outros $18,1 \%$ faz ou recebem em casa de algum produtor e 45,8 \% optam pela embalagem plástica. Em relação ao tipo 93,4 \% dos indivíduos preferem o doce de leite cremoso e 6,6 \% em barra. A embalagem pode ser explicada pelo fator preço, que foi uma preocupação de $62,5 \%$ dos consumidores, ficando atrás somente de qualidade sensorial com $73 \%$. 
Figura 3. Local de aquisição do leite condensado, doce de leite e sobremesa láctea.

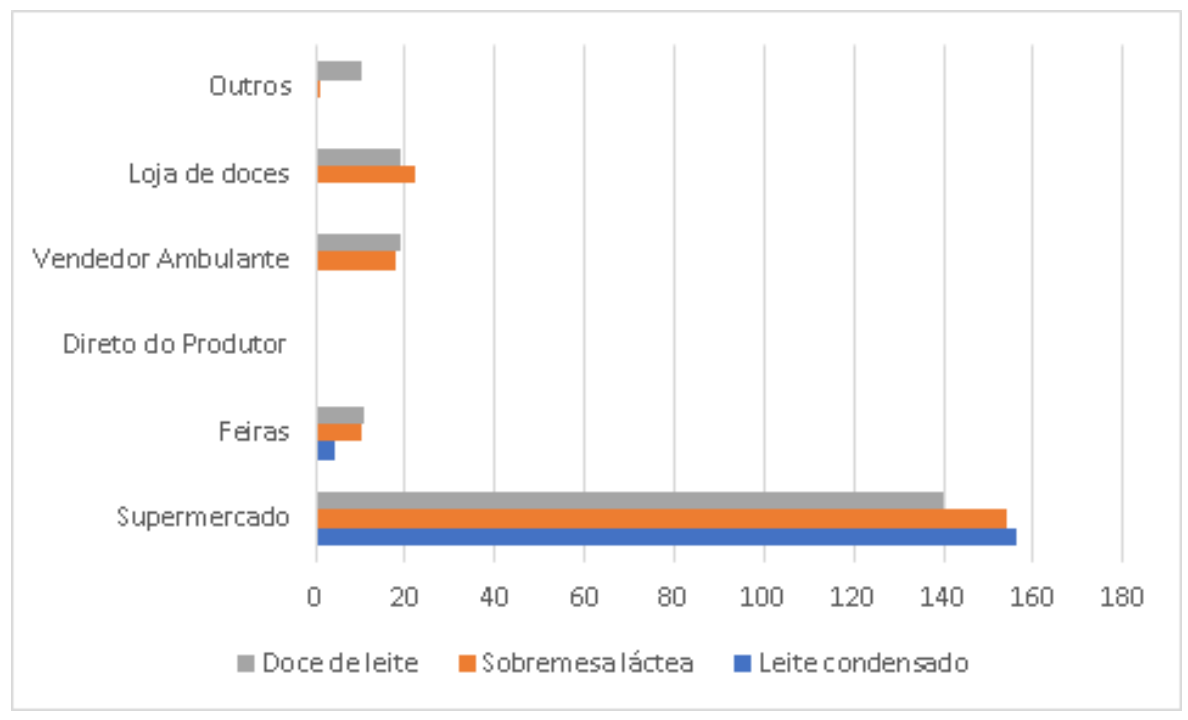

Fonte: Própria (2020)

A predominância na hora da escolha da embalagem de sobremesas lácteas são as de pote plástico (54,8\%), que está diretamente relacionado com a preferência de 79,6\% dos indivíduos por sorvete, seguidos de 59,2 \% pudim, $58 \%$ mousse, sendo adquiridas 98,1 \% das vezes em supermercado. Em relação ao sabor (Figura 4), 78,3 \% dos indivíduos declararam que tem preferência por chocolate, outros 47,8 \% morango, 36,5 $\%$ leite, $23,5 \%$ limão, 26,1 \% pelo sabor de coco, e ainda a minoria que gosta da de ameixa, baunilha cajá, creme e maracujá. Segundo França (2020) Mais de 20\% das vendas são dos sorvetes tradicionais, como chocolate, creme por exemplo. No entanto, o de leite ninho que está no mercado há quase dois anos vem crescendo. E como todo mundo já deve ter uma ideia, os de frutas também são bastante procurados no verão. Já no inverno, os sorvetes recheados é que são mais consumidos. 
Figura 4. Preferência de sabor das sobremesas lácteas.

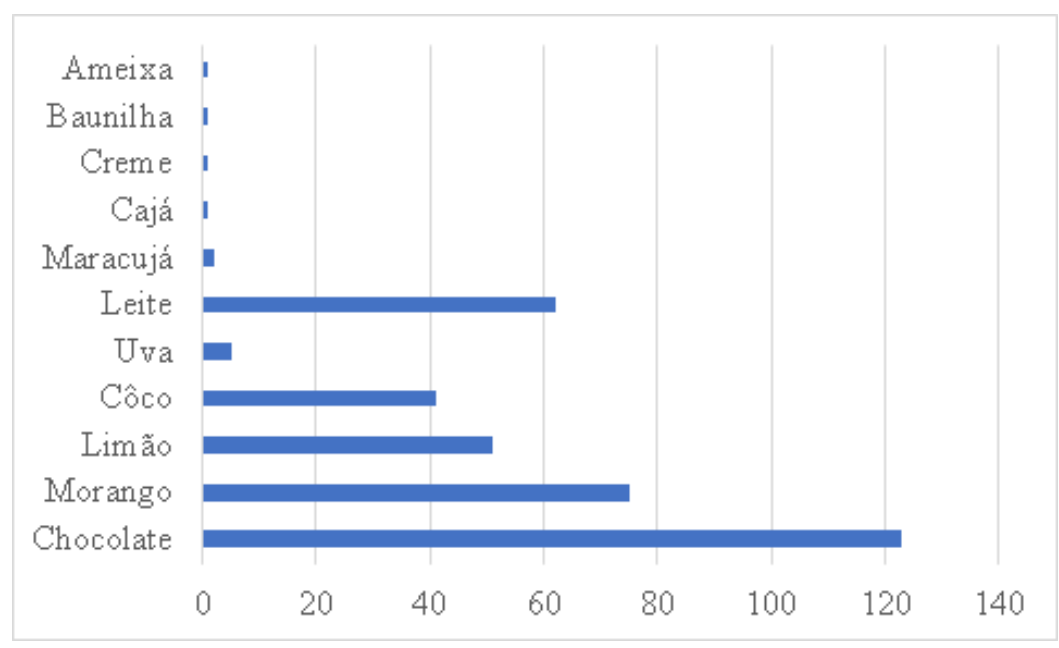

Fonte: Própria (2020)

O consumo de doce de leite (Figura 5), na maior parte, é realizado como opção de sobremesa $(54,8 \%, 67,5 \%, 75,8 \%$, respectivamente), seguido por aqueles que tem preferência em comer puro $(59,2 \%, 61,1 \%, 43,9 \%$, respectivamente) e $28,7 \%$ dos indivíduos consome como acompanhamento tanto para o doce de leite como para a sobremesa láctea. O leite condensado dentre os três foi o que teve maior índice de consumo como uso culinário $(60,0 \%)$. Aproximadamente $50 \%$ dos entrevistados relataram consumi-lo como acompanhamento para salada de fruta, e $(48,0 \%)$ como forma de lanche.

Figura 5. Forma de consumo dos produtos lácteos.

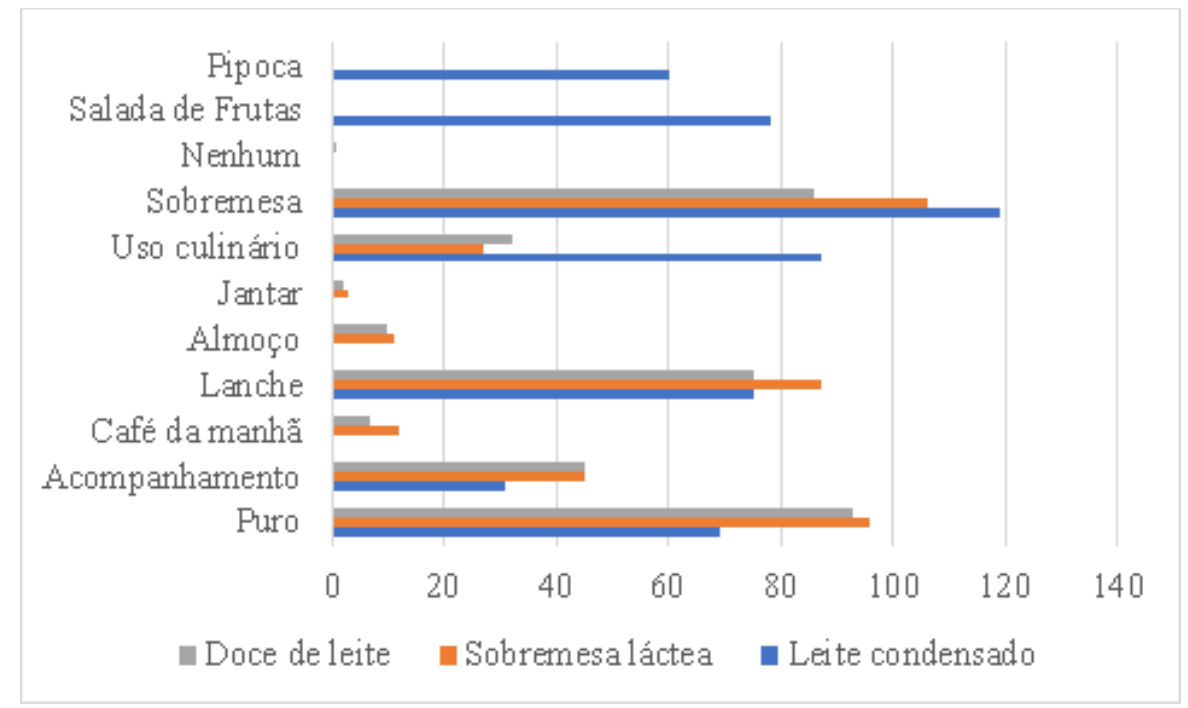

Fonte: Própria (2020).

[772] 
Quando questionados sobre o que tinha de importância para eles no processo produtivo (Figura 6) dos produtos a maioria dos indivíduos se demonstrou preocupados com a higiene tendo uma média de $86,5 \%$ e pelo sistema de inspeção $(46,9 \%)$. Cerca de $30,0 \%$ dos indivíduos demonstrou preferência por aqueles produtos que o leite utilizado no preparo é o pasteurizado, outros $28,1 \%$ prefere o doce de leite e o leite condensado do tipo artesanal. Menos de $1 \%$ dos indivíduos declararam não ter preferência. Mostra que (SILVA; DUTRA; CADIMA, 2010) estavam certos ao dissertar sobre um consumidor que está cada dia mais preocupado com sua saúde e exige que os alimentos sejam saborosos e seguros, bem como é regido pela legislação

Figura 6. Fator de importância no processo produtivo dos alimentos para os consumidores.

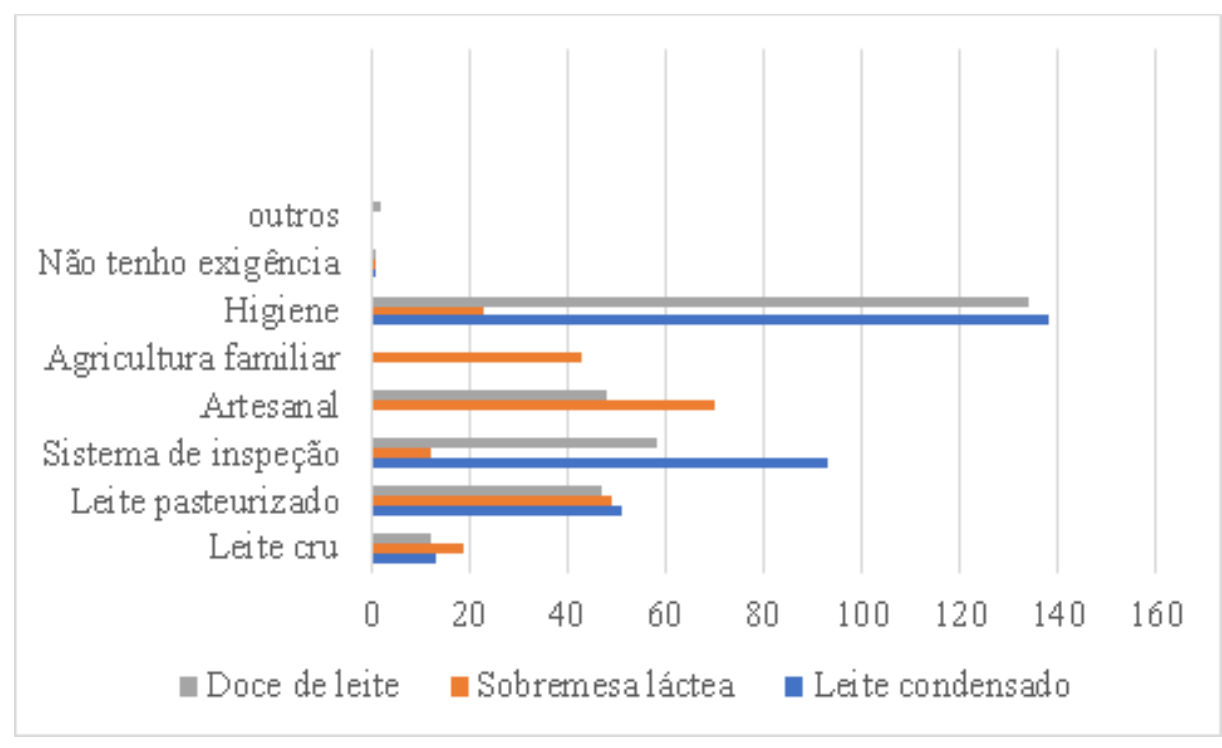

Fonte: Própria (2020)

No momento da compra do doce de leite, leite condensado e/ou sobremesas lácteas o que tem mais peso e o que os indivíduos costumam se preocupar (Figura 7) primeiramente é com a qualidade sensorial $(73,9 \%)$, seguido pelo preço $(61,1 \%)$, segurança que a marca transparece (higiene, livre de contaminantes, riscos...)(57,3\%), a origem do produto $(36,3 \%)$, informações presente no rótulo ( $28,0 \%$ ) assim como características nutricionais $(16,6 \%$ ), se possui ou não o sistema de inspeção (municipal, estadual e federal) $(27,4 \%)$ e ainda há aqueles que ficam divididos e observam a qualidade do produto e a marca $(1,2 \%)$.] 
Figura 7. Preocupação no momento da compra.

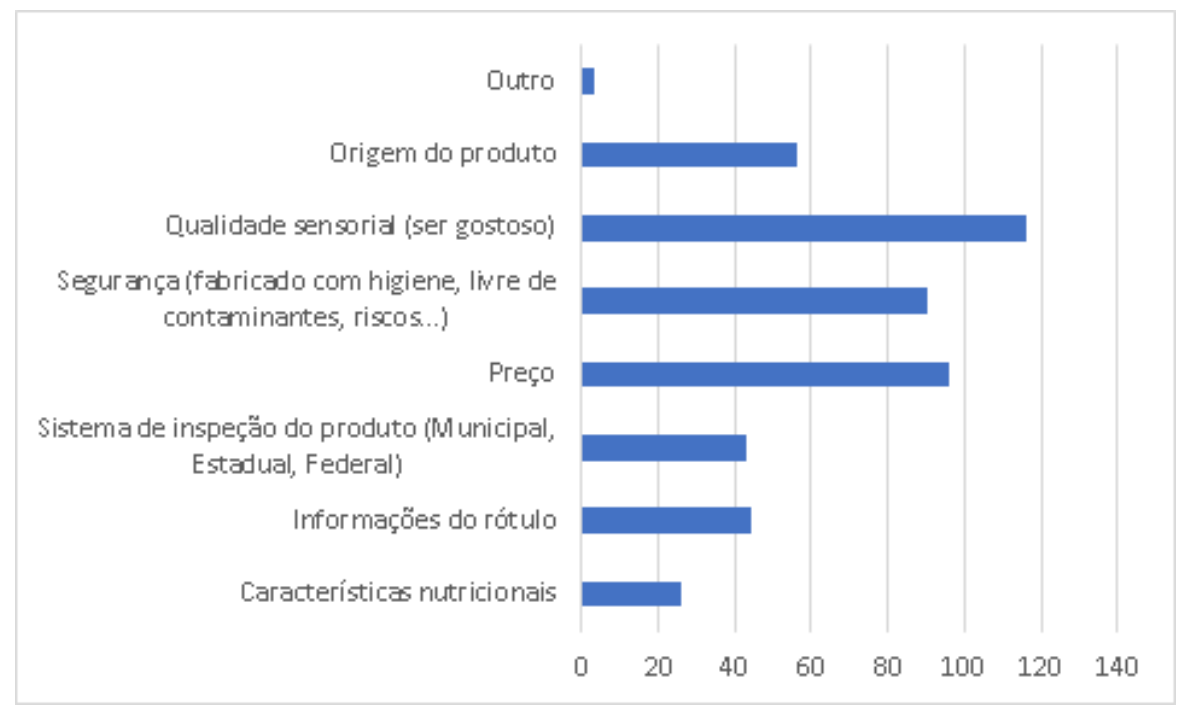

Fonte: Própria (2020)

Dos indivíduos que responderam o questionário 91,6 \% afirmam que a principal razão para consumir alguns dos três produtos se deve às características sensoriais, seguido pelo aroma $(33,1 \%)$, e ainda há aqueles que optem pelo consumo por acreditarem que traz benefícios a sua saúde $(8,3 \%)$. Ao serem questionados se estariam dispostos a pagar mais por um produto (Figura 8), 76,4\% afirmaram que pagariam mais, destes $54,1 \%$ por alimentos de origem artesanal, 39,5 \% orgânicos, 15,3\% light e 12,7 \% sem lactose. E os outros 23,6 \% afirmam que não estavam dispostos a pagar um valor maior. Quando perguntado o que seria um produto artesanal na opinião deles $84,1 \%$ considera um produto artesanal aquele que é feito de forma manual com o mínimo uso de equipamentos, $63,1 \%$ produzido pelo pequeno produtor, $36,3 \%$ produzido em pequena escala, $16,6 \%$ produzido a partir de leite cru, 3,2 \% com leite pasteurizado e $3,2 \%$ produzido de forma industrial em larga escala. O que nos revela que os alimentos artesanais são conhecidos por uma parte do público que participou do questionário e cada dia mais estão ganhando espaço no mercado. Porém alguns dos participantes ainda deixaram comentários que reforçam a necessidade de trabalho e divulgação desses alimentos, um dos comentários que chamou atenção:

"Existe uma grande desvalorização dos produtos artesanais e orgânicos, sendo difícil encontrar em mercados de cidades pequenas, se houvesse uma maior valorização desses produtos acabaria ajudando tanto a população que teria acesso a produtos diferente e 
muitas vezes mais "interessantes", e aos pequenos produtores que teriam um maior número de consumidores em potencial."

Figura 8. Sensibilidade ao preço e disposição do consumidor a pagar mais.

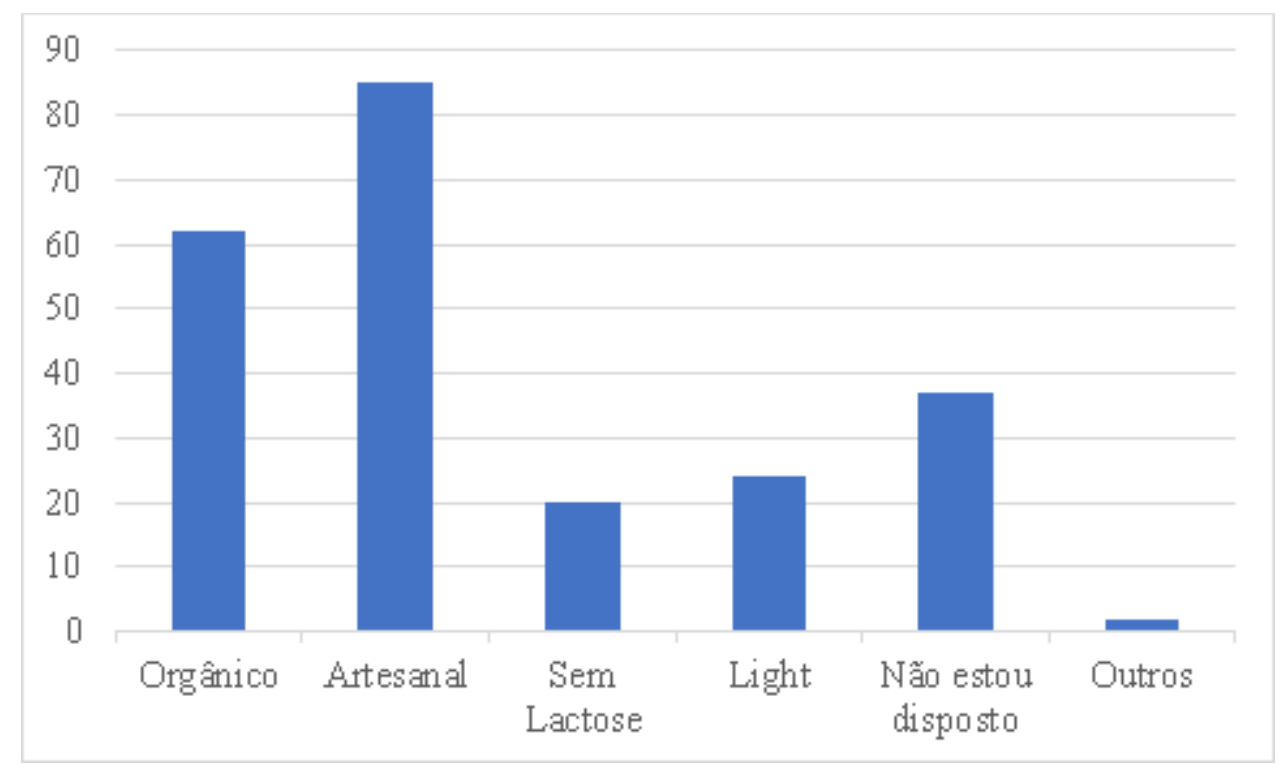

Fonte: Própria (2020)

Sendo o sabor e a marca os principais motivos para escolha do produto, visto que $66,2 \%$ compra por ser o mais gostoso e 59,2\% compra apenas de uma marca de confiança, $22,3 \%$ leva em consideração o preço, e ainda tem os que valorizam os produtos regionais $(18,5 \%)$. Outro ponto que se demonstrou importante na escolha dos produtos (Figura 9) é a opinião dos demais consumidores, uma vez que $21,7 \%$ compra o produto através de indicações e percepções de outros consumidores acerca do produto, assim como 0,6\% consome o produto pelo mesmo motivo. A percepção de outros consumidores já era discutida por Kotler e Keller (2012), que tratavam o comportamento dos outros como um fator fundamental, quando relacionado a atitudes e opiniões alheias que poderiam vir a ajudar ou atrapalhar na decisão de compra. 
Figura 9. Fatores de influência na escolha do produto.

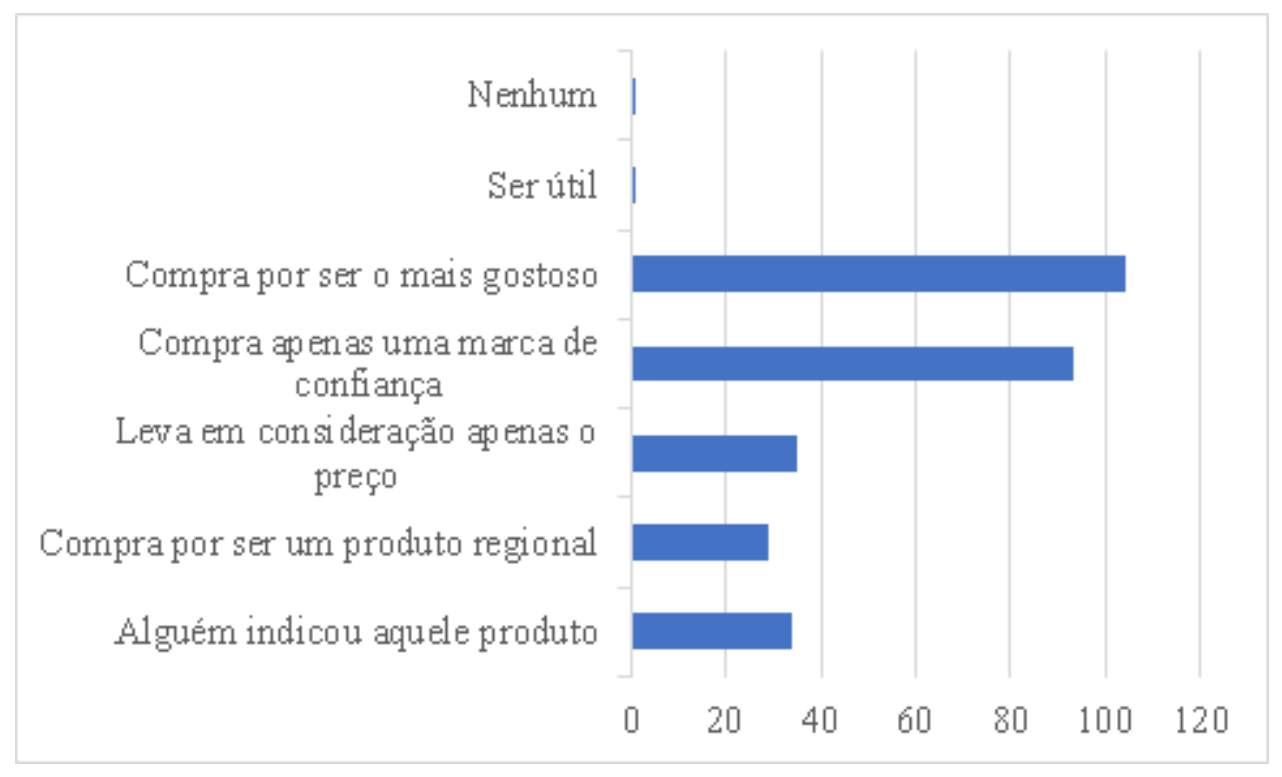

Fonte: Própria (2020)

Para efeito investigativo em cerca da pandemia que o Brasil atualmente enfrenta com a COVID-19, os 157 indivíduos foram questionados inicialmente se notou ou não um aumento no consumo (Figura 10) do doce de leite, leite condensado e sobremesas lácteas 44,6\% dos indivíduos perceberam um aumento do consumo desses produtos dentro o atual quadro que o país inteiro se encontra, 26,1 \% um pouco, 21,0 \% não, 8,3 $\%$ talvez. A grande maioria (65,5 \%) (103) não notou dificuldade (Figura 11) alguma em adquirir algum desses produtos, enquanto $20,4 \%$ acreditam que sim e desses $(22,14 \%)$ assimila isso a pandemia, e outros $14 \%$ não souberam responder. 
Figura 10. Aumento de consumo de doce de leite, leite condensado e sobremesa Láctea no período de pandemia. (Você notou se houve um aumento no valor de algum desses produtos? Acredita que está relacionado com o quadro atual em que o Brasil se encontra?)

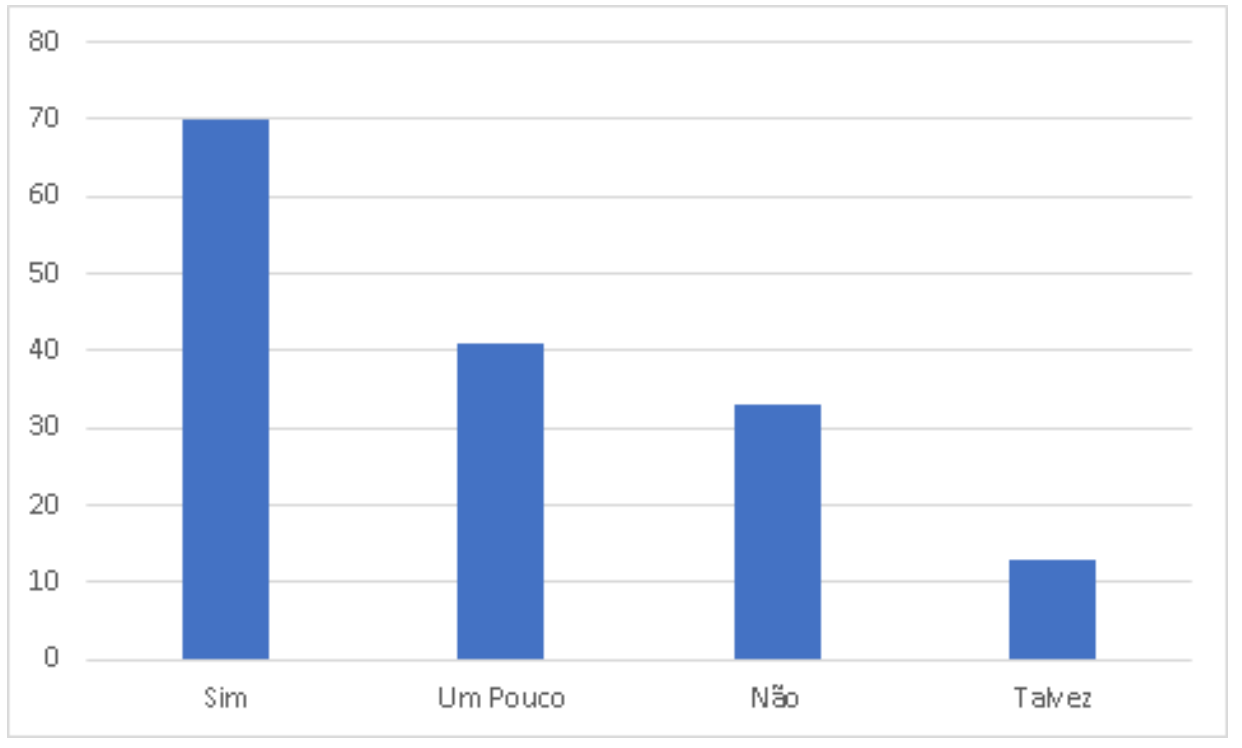

Fonte: Própria (2020).

Figura 11. Dificuldade na aquisição dos alimentos. (Você acredita que exista alguma dificuldade em adquirir o produto ou a falta do mesmo?).

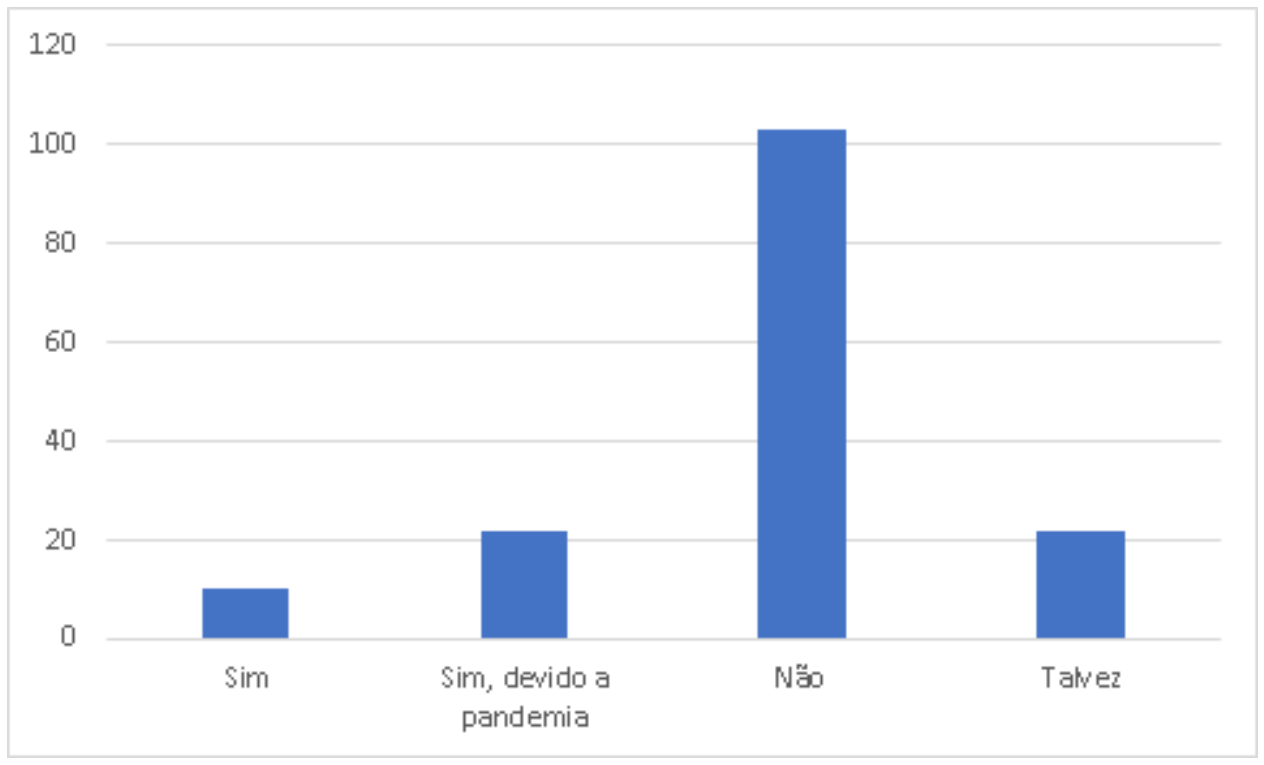

Fonte: Próprio (2020)

Em relação a precificação acerca dos produtos (Figura 12) devido à dificuldade em torno da produção e distribuição destes $63,1 \%$ dos indivíduos notaram um aumento no valor de algum desses produtos e acredita que esteja relacionado com a pandemia, 4,5 
\% afirmam ter tido o aumento mas acreditam que não esteja relacionado com a pandemia e $14 \%$ não notaram aumento algum e 18,5\% ficaram na dúvida (Figura 13).

Figura 12. Percepção acerca da precificação do doce de leite, leite condensado e sobremesa Láctea. (Você notou se houve um aumento no valor de algum desses produtos? Acredita que está relacionado com o quadro atual em que o Brasil se encontra?).

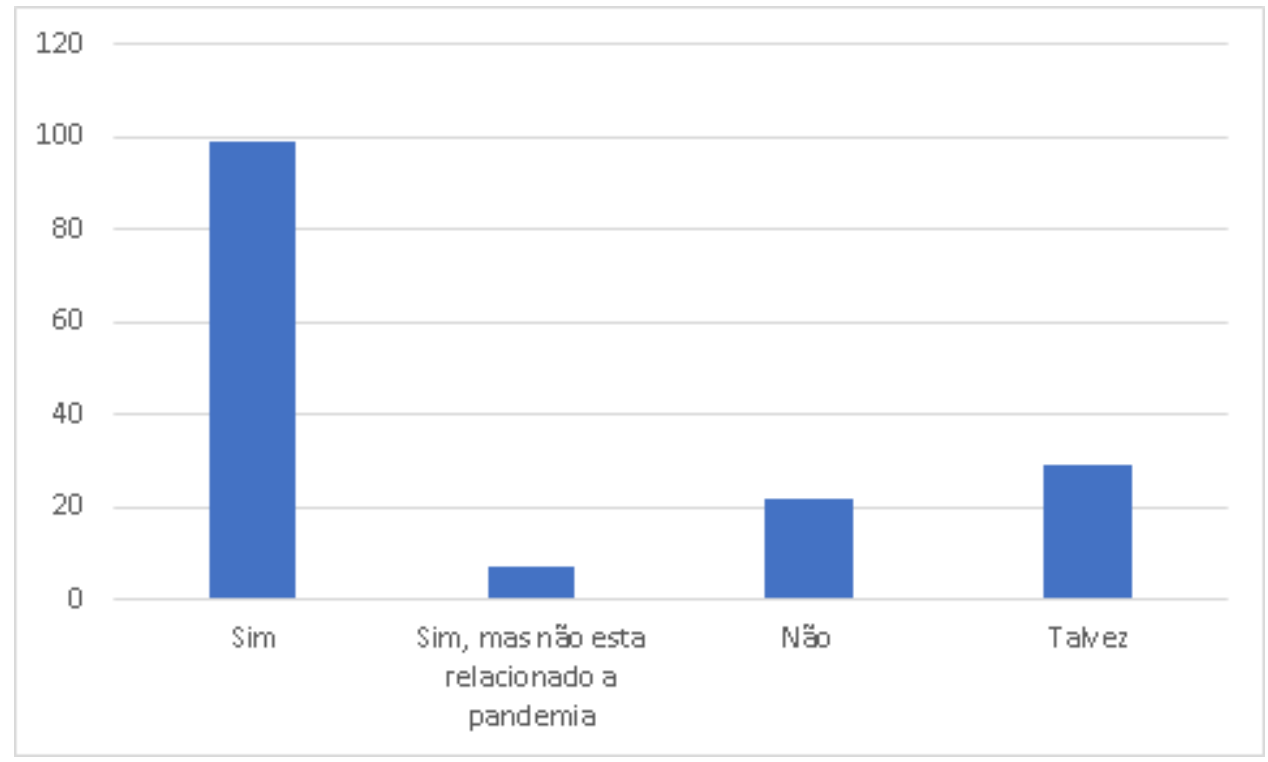

Fonte: Própria (2020)

Figura 13. Comparativo entre o acréscimo no consumo, dificuldade em adquirir e o aumento no valor dos produtos.

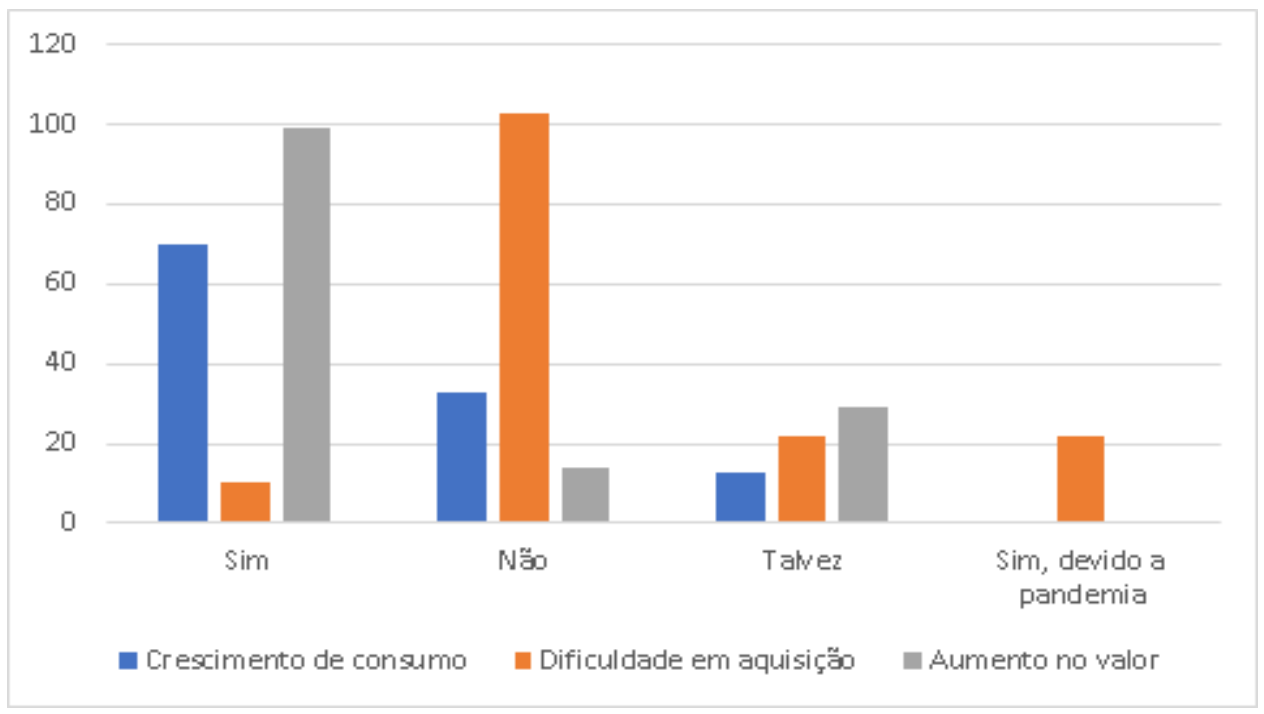

Fonte: Próprio (2020)

[778]

CIÊNCIA, TECNOLOGIA E INOVAÇÃO: DO CAMPO À MESA. RECIFE: EDITORA IIDV, 2020 


\section{Conclusões}

O resultado deste estudo destaca-se por apresentar o debate sobre o que motiva $o$ público respondente a consumir os produtos doce de leite, leite condensado e sobremesas lácteas e a relação entre o aumento ou diminuição destes na rotina do convívio com a pandemia. Observou-se a carência de pesquisas voltadas e este nicho de mercado nas condições de distanciamento e isolamento sociais quanto ao consumo de derivados do leite e as indústrias de laticínios para buscar entender os impactos de interesses e dificuldades dos consumidores, bem como, obter respostas para melhor ajudar às indústrias no que diz respeito à compreensão e fortalecimento na relação com seus clientes. As pesquisas de satisfação, inovação e confiabilidade são fatores de influência na hora da compra de um produto alimentício. foi possível identificar que o consumo de doce de leite, leite condensado e sobremesas lácteas acontecem na maior parte dos casos por jovens entre 16 e 25 anos para o preparo de sobremesas ou como acompanhamento, e que os usuários estão atentos a indicações de marca e a relação de qualidade e preço, buscando pelo custo-benefício.

Deste modo pode-se afirmar que os objetivos do artigo foram alcançados pois foi possível identificar que o consumo de doce de leite, leite condensado e sobremesas lácteas acontecem na maior parte dos casos por jovens entre 16 e 25 anos para o preparo de sobremesas ou como acompanhamento, e que os usuários estão atentos a indicações de marca e a relação de qualidade e preço, buscando pelo custo-benefício.

\section{Referências}

FRANÇA, Lucas. Calor aumenta vendas de sorvetes. Tribunahoje, Macéio-Alagoas, n. 3558, 11 jan. 2020. Cidades, p. 13. Disponível em: https://issuu.com/tribunahoje/docs/ed11e120120. Acesso em: 27 jul. 2020.

KOTLER, P.; KELLER K. L. Administração de Marketing. São Paulo: Pearson, 2012.

MINASSE, Maria Henriqueta Gimenes. Comfort food: sobre conceitos e principais características. Contextos da Alimentação - Revista de Comportamento, Cultura e Sociedade, São Paulo, v. 4, n. 2, 2016.

SCHUBERT, Maycon Noremberg. Hábitos alimentares em tempos de mudanças provocadas pela Covid-19. Porto Alegre: UFRGS, 30 mar. 2020. Disponível em: https://www.ufrgs.br/ifch/index.php/br/habitos-alimentares-em-tempos-de-mudancasprovocadas-pela-covid-19. Acesso em: 28 jul. 2020. 
SEBRAE (Brasil). Tristeza e indulgência. OS ASPECTOS DA INDULGÊNCIA NO CONSUMO DE PANIFICADOS E CONFEITARIA, Brasília, p. 4-10, 2017. Disponível em: https://bis.sebrae.com.br/bis/conteudoPublicacao.zhtml?id=19205. Acesso em: 18 jul. 2020.

SEBRAE (Pernambuco). Produção de leite na Região Nordeste e seus estados. CENÁRIOS PARA O LEITE E DERIVADOS NA REGIÃO NORDESTE EM 2020, Recife, p. 154, 2013.

SILVA, Gilvan; DUTRA, P.R.S; CADIMA, I.M. Higiene na Indústria de Alimentos. Curso técnico em alimentos- Modalidade a distância, Recife, p. 16, 2010.

UNIVERSIDADE FEDERAL DE JUIZ DE FORA (Juiz de Fora). Estudo analisa consumo de derivados lácteos durante a quarentena. Pesquisa e Inovação, Juiz de Fora, 27 abr. 2020. Disponível em: https://www2.ufjf.br/noticias/2020/04/27/estudo-analisaconsumo-de-derivados-lacteos-durante-a-quarentena/. Acesso em: 18 jul. 2020.

WANSINK, Brian; CHENEY, Matthew; CHAN, Nina. Exploring comfort food preferences across age and gender. In: Physiology \& behavior, 2003, 79, p.739-743. 